Article

\title{
Optimization of LED Lighting and Quality Evaluation of Romaine Lettuce Grown in An Innovative Indoor Cultivation System
}

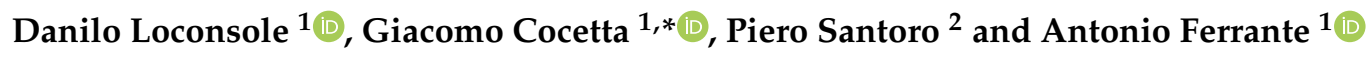 \\ 1 Department of Agricultural and Environmental Sciences-Production, Landscape, Agroenergy, \\ Università degli Studi Milano, via Celoria, 2, 20133 Milano, Italy; danilo.loconsole@hotmail.it (D.L.); \\ antonio.ferrante@unimi.it (A.F.) \\ 2 MEG S.r.l., via Aleardo Aleardi 12, 20154 Milano, Italy; santoro@growmeg.org \\ * Correspondence: giacomo.cocetta@unimi.it
}

Received: 3 January 2019; Accepted: 30 January 2019; Published: 6 February 2019

\begin{abstract}
Sustainability is the most critical point in micro-scale indoor crop systems. It can be improved through the optimization of all of the production factors, such as water, nutrients, and energy. The use of light-emitting diodes (LED) allows the fine regulation of the light intensity and light spectrum to be obtained, with a significant reduction in energy consumption. The objective of this study was the optimization of a LED-based protocol of light management for Romaine lettuce cultivation in a micro-growing environment specifically designed for home cultivation. Four different growing cycles were tested. In each one, the light spectrum was modified by increasing the percentage of red light and decreasing the blue light. This resulted in a change in the light intensity which ranged from 63.2 to $194.54 \mu \mathrm{mol} \mathrm{m}{ }^{-2} \mathrm{~s}^{-1}$. Moreover, the photoperiod was shortened to reduce the energy consumption and, in the last cycle, the effect of the daily alternation of dark and light was tested. The fresh and dry biomass produced were measured and the energy consumed in each cycle was monitored. The quality of lettuce was evaluated by measuring several physiological indexes, including chlorophyll $a$ fluorescence, chlorophyll, sugars, nitrate, lipid peroxidation, carotenoids, and phenolic index. The results obtained showed that the productivity and the quality of lettuce can be positively affected by modulating the light quality and intensity, as well as other cultural practices. At the same time, the estimation of the electrical energy consumption indicated that little changes in the lighting recipe can significantly affect the energetic, environmental, and economic impact of home productions.
\end{abstract}

Keywords: hydroponic; Lactuca sativa L.; leafy vegetables; light-emitting diodes; micro-growing; solid-state lighting

\section{Introduction}

In the last few years, the use of solid-state lighting (SSL) technology has largely grown in several industrial sectors, including agriculture. Light-emitting diodes (LED) technology is based on the use of electronic devices built with semiconductor materials which efficiently convert the electricity into light. The use of LED-based equipment allows the modulation of the intensity and the composition of the light spectrum [1], thus enabling the optimal lighting condition for a specific crop at each developmental stage to be set, optimizing plant growth in the most energy-efficient way [2]. Moreover, modern informatic tools allow the setting of complex light recipes, through the selection of the most appropriate spectral composition in a very accurate manner. Using LED as a light source, it is possible to control each wavelength separately within quite a narrow range (around $40 \mathrm{~nm}$ of accuracy for each 
bandwidth) compared to the traditional bulb lamps. Moreover, LED lamps facilitate the consumption of less energy (up to 70\%) compared to traditional light sources [3,4], as LED lights operate at a lower temperature, have a reduced impact on the growing environment, and generally have a longer lifetime.

Specific kinds of light have been reported to be effective in promoting plant growth or affecting plant morphology. Red and blue are generally recognized as the most important light regions necessary for plant development and growth [5], however, other wavelengths (such as those corresponding to yellow or green colors) could also have a role in affecting the quality of crops [6]. Red light promotes biomass accumulation, growth, and photosynthesis in lettuce [7]. Lee et al. [8] showed that the low red/far-red (R:FR) ratio influences growth, plant structure, and root exudate's emission. Far-red light was reported to be effective in promoting biomass accumulation and leaf length when combined with red LED or with cool white fluorescent light $[9,10]$. Blue LED light is effective in stimulating photomorphogenesis and adaptive phenomena like the stomata opening/closing regulation mechanism, as well as biomass accumulation and chlorophyll and anthocyanin biosynthesis [5,9]. Green LED light regulates leaf expansion, stem stretching, and stomatal conductance. Moreover, it has been shown that green LED light leads to greater dry mass accumulation and growth stimulation [11].

The possibility of modulating the spectrum of LED lighting can also help in promoting the accumulation of important plant metabolites which are often associated with the nutraceutical properties, as recently shown in lettuce [8] and in the commercial quality of leafy crops. Red light has been shown to promote anthocyanin accumulation in leaf red cabbage [12] and to increase the concentration of phenolics in lettuce [9]. On the other hand, a low R:FR ratio has been reported to reduce the chlorophyll content in several crop species [13]. The use of specific light intensities can also promote a reduction in the concentration of potentially harmful molecules. In fact, LED light plays a role in controlling the nitrate content, which is a key aspect related to the quality of leafy greens [14]. Continuous light and/or mixed light (red, blue, and green) have been hypothesized to reduce the nitrate content in lettuce [15]. Red light is thought to stimulate the activity of the enzyme nitrate reductase, facilitating nitrate assimilation and metabolism [16].

Interest in the use of LED lights and indoor cultivation systems is growing, as well as the concern about the environmental impact, the energy costs, and the quality of the produce that can be obtained [1,17]. It is generally thought that this kind of system cannot economically compete with traditional greenhouse cultivation. However, domestic cultivation meets the expectations of those consumers that are looking for highly fresh produce, food self-sufficiency, or simply hobby pursuit. On a larger scale, vertical farming is a novel cultivation concept that aims to increase the plant productivity per unit area of cultivated land and is based on the use of LED lighting, similar to micro-growing systems. In addition, scientific effort is being made to develop new strategies for growing higher plants in extreme conditions (like on the Moon or Mars) in closed cultivation systems largely based on the use of hydroponics and LED lighting [18]. For these reasons, the set-up and optimization of plant-specific protocols for cultivation is a crucial step in improving the sustainability of indoor growing systems. The sustainability of the production system depends on the efficient use of natural resources, such as energy, water, and fertilizers. In closed cultivation systems, such as vertical farms, the resource use efficiency must be higher in than greenhouses or conventional agricultural systems, mainly because a more rational use of water, cultivated area, and fertilizer is obtained at the expense of additional energy consumption [19].

To date, the scientific literature is offering a large number of exhaustive review papers on the use of different light spectra and their possible applications in protected environments [3,6,20], but little information is available on the optimization of cultivation protocols on a micro-growing scale. It has been recently shown that even though numerous experiments have been conducted, the problem of lighting regime optimization for micro-scale plant growth units equipped with LEDs still exists [21].

The objective of this study was to determine the optimal protocol for LED management for the indoor production of lettuce using an experimental micro-growing system. Four different growing 
cycles were tested. In each cycle, the light spectrum was modified by increasing the percentage of red light and decreasing the percentage of blue light. This resulted in a change in the light intensity, which ranged from 63.2 to $194.54 \mu \mathrm{mol} \mathrm{m}^{-2} \mathrm{~s}^{-1}$. Moreover, the photoperiod was shortened to reduce the energy consumption and, in the last cycle, the effect of the daily alternation of dark and light was tested.

A recent study conducted on lettuce was focused on the changes induced by different ratios of red and blue light, with particular attention on the primary metabolism (i.e., photosynthetic performance) [22]. In another study, the short-term (24 h) effect of LED light supplementation was observed, in terms of on the reduction in nitrate and the increment in phenolic compounds [1]. In the present study, the quality of lettuce was evaluated by measuring several physiological indexes, including chlorophyll $a$ fluorescence, total chlorophyll, total sugars, nitrate, lipid peroxidation, total carotenoids, and the phenolic index. In addition, the energy consumption and biomass production were used to determine the efficiency and the sustainability of a given protocol of cultivation.

\section{Materials and Methods}

\subsection{Plant Material and Growing Conditions}

Four cultivation cycles were performed, each of which was characterized by subsequent light adjustments following crop responses. For each cycle, two-week-old lettuce (Lactuca sativa L. var. longifolia) seedlings were transplanted into air-pots filled with rock wool. Immediately after transplantation, four plants were moved to the experimental growing chamber equipped with an LED-based illumination system (MEG ${ }^{\circledR}$-Micro Experimental Growing). MEG ${ }^{\circledR}$ is a LED-based, open-source, automated, indoor greenhouse, developed for home growing and indoor uses. This device utilizes a precision illumination system, composed of LED diodes managed by a smart control system which allows the modulation of the light spectrum composition and the light intensity. Moreover, $\mathrm{MEG}^{\circledR}$ was equipped with two $50 \mathrm{~L}$ tanks for the nutrient solution, a ventilation system, a humidity control system, and an oxygen supply system for the nutrient solution. Plants were grown hydroponically, using an optimized Hoagland's solution. The concentrations of nutrients in the solution (expressed as mM) were: $12 \mathrm{~N}^{-\mathrm{NO}_{3}}, 3.8 \mathrm{~N}-\mathrm{NH}_{4}, 2.8 \mathrm{P}, 8.4 \mathrm{~K}, 3.5 \mathrm{Ca}, 1.4 \mathrm{Mg}$, and Hoagland's solution for micronutrients. The electric conductivity (EC) and $\mathrm{pH}$ were monitored during the whole growing cycle.

More details regarding the growing conditions and the light spectrum composition in each cycle are specified in Table 1 . The specific light spectra were measured for each growing cycle by using a portable spectroradiometer (Everfine, PLA 20) and are reported in Figure 1. The light spectra measured were divided into three macro-regions: Red $(600-780 \mathrm{~nm})$, green and yellow $(500-600 \mathrm{~nm})$, and blue (400-500 nm). For this reason, the light percentages shown in Table 1 have been divided into three groups. Different light settings resulted in different photosynthetic photon flux densities (PPFDs), as reported in Table 1 . The energy consumption (Wh) was measured for each growing cycle using a plug digital wattmeter (Table 1).

At the end of each cycle, in vivo analysis of chlorophyll $a$ fluorescence was performed, then samples were collected and immediately stored at $-20{ }^{\circ} \mathrm{C}$ for further analytical evaluations. The analysis of chlorophyll $a$ fluorescence was performed on six leaves, while three biological replicates were collected for the other analyses described. After the initial evaluation of the stress responses in the plants during the first growing cycle, a second set of analyses on the total sugars, nitrate content, and the phenolic index were performed in a further evaluation conducted on samples from Cycles 2, 3, and 4. Plants from Cycle 1 were not included in this second set of analyses, mainly because they showed marked signs of stress and pronounced alterations in the leaf morphology (Supplementary Figure S1). 
Table 1. The growing conditions applied to the cultivation of Romaine lettuce in the experimental micro-growing lighting system.

\begin{tabular}{|c|c|c|c|c|c|c|c|c|c|}
\hline Cycle & Length (days) & $\begin{array}{l}\text { Relative Humidity } \\
\text { (RH \%) }\end{array}$ & $\begin{array}{c}\text { Light Period } \\
\text { Temperature }\left({ }^{\circ} \mathrm{C}\right)\end{array}$ & $\begin{array}{c}\text { Dark Period } \\
\text { Temperature }\left({ }^{\circ} \mathrm{C}\right)\end{array}$ & $\begin{array}{l}\text { Photosynthetic Photon } \\
\text { Flux Density (PPFD) } \\
\left(\mu \mathrm{mol} \mathrm{m} \mathrm{m}^{-2} \mathrm{~s}^{-1}\right)\end{array}$ & $\begin{array}{c}\text { Hours of } \\
\text { Light }\end{array}$ & R:G + Y:B (\%) * & Light Spectrum (nm) & $\begin{array}{c}\text { Energy } \\
\text { Consumption (Wh) }\end{array}$ \\
\hline 1 & 25 & $50 \pm 2$ & $22 \pm 1$ & $19 \pm 1$ & 194.54 & $6 \mathrm{am}-10 \mathrm{pm}$ & 69.9:17.0:13.1 & $460 ; 470 ; 590 ; 630 ; 670$ & $128 \pm 1$ \\
\hline 2 & 31 & $50 \pm 2$ & $22 \pm 1$ & $19 \pm 1$ & 151.41 & $6 \mathrm{am}-8 \mathrm{pm}$ & 73.0:20.1:6.9 & $\begin{array}{c}\text { 460; 470; 590; 630; 670; } \\
\text { White 4000k }\end{array}$ & $120 \pm 1$ \\
\hline 3 & 27 & $50 \pm 2$ & $20 \pm 1$ & $17 \pm 1$ & 165.89 & $6 \mathrm{am}-8 \mathrm{pm}$ & 77.1:17.9:5 & $\begin{array}{c}\text { 460; } 470 ; 590 ; 630 ; 670 ; \\
\text { White 4000k }\end{array}$ & $116 \pm 1$ \\
\hline 4 & 28 & $50 \pm 2$ & $20 \pm 1$ & $17 \pm 1$ & $165.89 / 63.2^{* *}$ & $6 \mathrm{am}-8 \mathrm{pm}$ & 77.1:17.9:5/79.1:16.6:4.3** & $\begin{array}{c}\text { 460; 470; 590; 630; 670; } \\
\text { White 4000k }\end{array}$ & $116 / 70 \pm 1^{* *}$ \\
\hline
\end{tabular}

* R: red, G: green, Y: yellow, B: blue. ** alternate each hour.

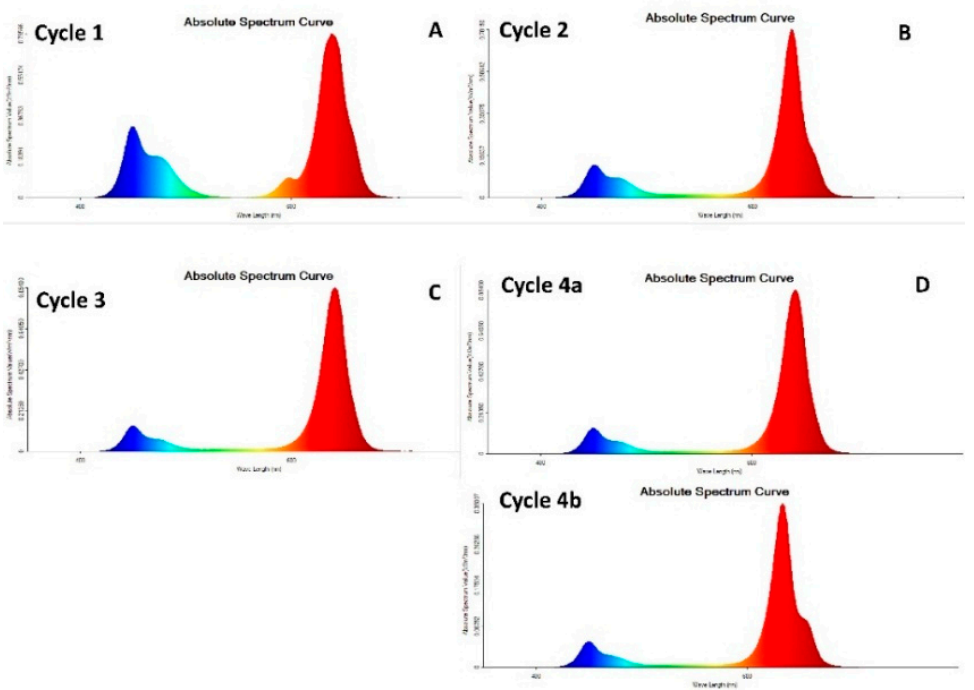

Figure 1. The light spectra utilized for each growing cycle. Cycle 1 (A), Cycle 2 (B), Cycle 3 (C). Note that Cycle 4 (D) is characterized by the alternate change of the two spectra shown $(\mathrm{a}$ and $\mathrm{b})$. The detailed information regarding each growing cycle is reported in Table 1. 


\subsection{Chlorophyll a Fluorescence}

The chlorophyll $a$ fluorescence was measured on dark-adapted (30 $\mathrm{min}$ ) leaves using a portable fluorimeter (Handy PEA; Hansatech, Kings Lynn, UK). Measurements were taken on the leaf's surface ( $4 \mathrm{~mm}$ diameter), which was exposed to an excitation light intensity of $3000 \mu \mathrm{mol} \mathrm{m}^{-2} \mathrm{~s}^{-1}$ emitted by three diodes. The fluorescence detection was measured by a fast-response PIN photodiode with an RG9 long pass filter (Technical manual, Hansatech, Kings Lynn, UK). The parameters measured were the maximum quantum efficiency of photosystem II (Fv/Fm), the performance index (PI), and the number of reactive centers per cross-section (RC/CSm). Among these indexes, the PI represents a very useful general term, providing information concerning the relative leaf functionality. The PI includes three independent parameters: The density of the active reaction centers (RCs), the efficiency of electron transport, and the probability that an absorbed photon will be trapped by the RCs [23].

The measurement of light-adapted chlorophyll $a$ fluorescence was also performed, under environmental light conditions using a field portable pulse modulated chlorophyll fluorimeter (FMS2, Hansatech, Kings Lynn, UK).

\subsection{Measurement of the Absorption Spectrum of Leaves}

The absorption spectrum of leaves was determined using a bench spectrophotometer (Thermo Fisher Vision 300, UV-VIS). Leaf strips $(45 \times 12.5 \mathrm{~mm})$ were placed in the cuvette and the absorbance spectrum was recorded from 30 to 760 , in order to identify the absorbance in the 400-700 nm region (PAR). The spectrum represents the relative optical density (O.D.) measured for each wavelength from $400-700 \mathrm{~nm}$.

\subsection{Plant Biomass Measurement and Estimation of the Input of Electrical Energy Consumed for Lettuce Production}

The fresh weight was determined in leaves and roots separately. For the dry weight measurements, the leaf and root samples were kept in an oven at $105^{\circ} \mathrm{C}$ until all of the water was evaporated (constant weight) and the dry mass was then estimated as a percentage compared to the fresh weight.

The input of electrical energy consumed for the lettuce production was estimated for each cycle, considering the total leaf biomass produced by four plants, the length of each cycle, the hours of light, and the energy consumed per hour. The result obtained has been reported in $\mathrm{kWh} \mathrm{Kg}^{-1}$.

\subsection{Quality and Physiological Evaluation of Lettuce under Different Growing Conditions}

Lipid peroxidation was achieved by using the thiobarbituric acid reactive substances (TBARS) method [24]. One gram of tissue was homogenized in $5 \mathrm{~mL}$ of trichloroacetic acid (TCA) of $0.1 \% \mathrm{w} / \mathrm{v}$ and centrifuged at $4000 \mathrm{rpm}$ for $10 \mathrm{~min}$. One $\mathrm{mL}$ of the supernatant was mixed with $4 \mathrm{~mL}$ of $20 \%$ $(w / v)$ TCA, $25 \mu \mathrm{L}$ of $0.5 \%$ thiobarbituric acid (TBA), and distilled $\mathrm{H}_{2} \mathrm{O}$. After vortexing, the mixture was heated at $95^{\circ} \mathrm{C}$ for $30 \mathrm{~min}$ in a water bath and then cooled on ice. An absorbance at $600 \mathrm{~nm}$ was subtracted from the absorbance at $532 \mathrm{~nm}$ (as an index of non-specific turbidity) and the concentration of TBARS were expressed as malondialdehyde (MDA) equivalents ( $\mathrm{nmol} \mathrm{g}^{-1}$ F.W.), calculated by using the Lambert-Beer law with an extinction coefficient $\left(\varepsilon \mathrm{M}=155 \mathrm{mM}^{-1} \mathrm{~cm}^{-1}\right)$.

Total chlorophylls and carotenoids were extracted from the fresh leaf tissues (around $50 \mathrm{mg}$ ) using $5 \mathrm{~mL}$ of methanol $99.9 \%$ as the solvent. The samples were kept in a dark room at $4{ }^{\circ} \mathrm{C}$ for $24 \mathrm{~h}$. Absorbance readings were measured at 665.2 and $652.4 \mathrm{~nm}$ for chlorophyll pigments and $470 \mathrm{~nm}$ for total carotenoids. Chlorophyll and carotenoid concentrations were calculated using Lichtenthaler's formula [25].

Around $1 \mathrm{~g}$ of leaves were homogenized in $4 \mathrm{~mL}$ of distilled water and centrifuged at $4000 \mathrm{rpm}$ for $20 \mathrm{~min}$ at room temperature. A total sugars (TS) assay was performed on the obtained extract, according to the anthrone assay [26]. The absorbance was recorded at $620 \mathrm{~nm}$ and the calculation of the total sugar content was performed by using a glucose calibration curve at $0,1,2,3$, and $4 \mathrm{mM}$. 
The nitrate content was measured using the method of Cataldo et al. [27] with slight modifications. Around $1 \mathrm{~g}$ of the fresh sample was ground in with $4 \mathrm{~mL}$ of distilled water. The extract was centrifuged at $4000 \mathrm{rpm}$ for $15 \mathrm{~min}$ and the supernatant was recovered and used for the colorimetric determination. Twenty $\mu \mathrm{L}$ of the sample was added to $80 \mu \mathrm{L}$ of $5 \%$ salicylic acid in sulphuric acid and to $3 \mathrm{~mL}$ of $\mathrm{NaOH} 1.5 \mathrm{~N}$. The samples were cooled at room temperature and the readings were performed at $410 \mathrm{~nm}$. The nitrate content was estimated by referring to a $\mathrm{KNO}_{3}$ standard calibration curve.

For the extraction of the phenolic compounds, around $50 \mathrm{mg}$ of leaves were placed in $5 \mathrm{~mL}$ of acidified methanol $(1 \% \mathrm{HCl} v / v)$ and extracted overnight in the dark. The phenolic index was calculated as the absorbance measured at $320 \mathrm{~nm}$ [28].

\subsection{Statistical Analysis}

Data were subjected to a one-way analysis of variance (ANOVA) followed by Bonferroni's multiple comparisons test. Analyses were performed using GraphPad Prism version 6 for Windows (GraphPad Software; La Jolla, California, USA, www.graphpad.com).

\section{Results}

\subsection{Chlorophyll a Fluorescence}

The quantum maximum efficiency of the PSII (photosystem II (Fv/Fm)) was significantly higher in plants subjected to an alternate changing in high and low PPFD (Cycle 4) in comparison to those of Cycles 1 and 3 (Figure 2A). However, all of the plants showed values higher than 0.83, which is normally considered as a threshold between stressed and non-stressed tissue [29]. The performance index (PI) was markedly reduced in plants from Cycle 1 (Figure 2B), indicating a general loss in the performance of the PSII. No changes were observed in the number of reactive centers per cross-section (RC/CSm) (Figure 2C). Considering the analysis of the fluorescence performed in the real growing conditions (Figure 3A-D), the steady-state fluorescence yield (Fs), the maximum fluorescence yield $\left(\mathrm{Fm}^{\prime}\right)$, and the photochemical yield of photosystem II (ФPSII) were not significantly affected by the different growing conditions. On the other hand, the electron transport rate (ETR) was significantly higher in plants from Cycle 2, while the minimum value was recorded in Cycle 1, further indicating that the highest light intensity determined a loss in the performance of the PSII.

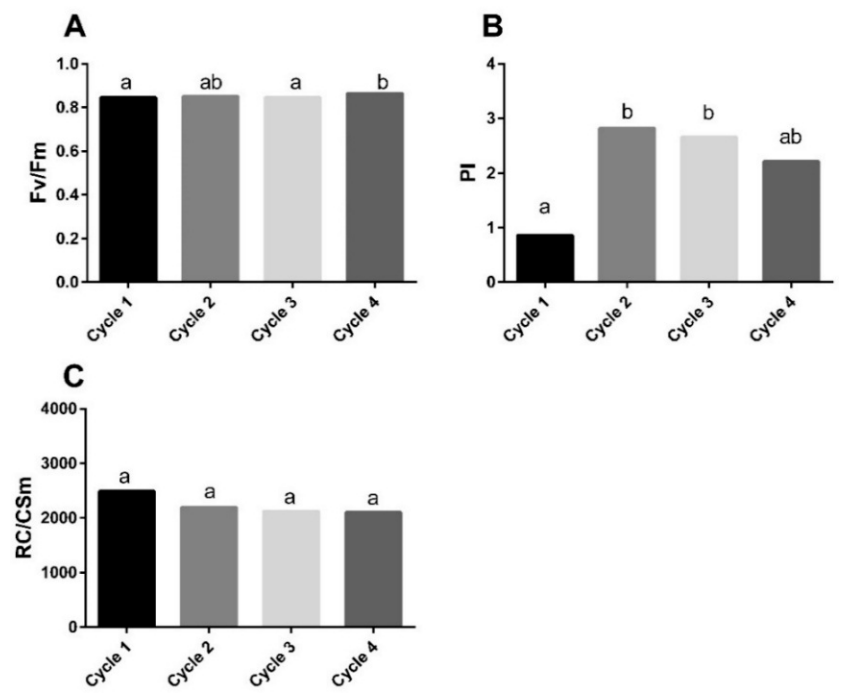

Figure 2. The chlorophyll $a$ fluorescence indexes measured in vivo on dark-adapted Romaine lettuce (Lactuca sativa L. var. longifolia) leaves grown under different growing conditions, as reported in Table 1. The maximum quantum efficiency of photosystem II (PSII (Fv/Fm)) (A), the performance index (PI) (B), and the number of reaction centers per cross-section $(\mathrm{RC} / \mathrm{CSm})(\mathrm{C})$. Values are means $\pm \mathrm{SE}(\mathrm{n}=6)$. Different letters indicate significant differences among different cycles $(p<0.05)$. 

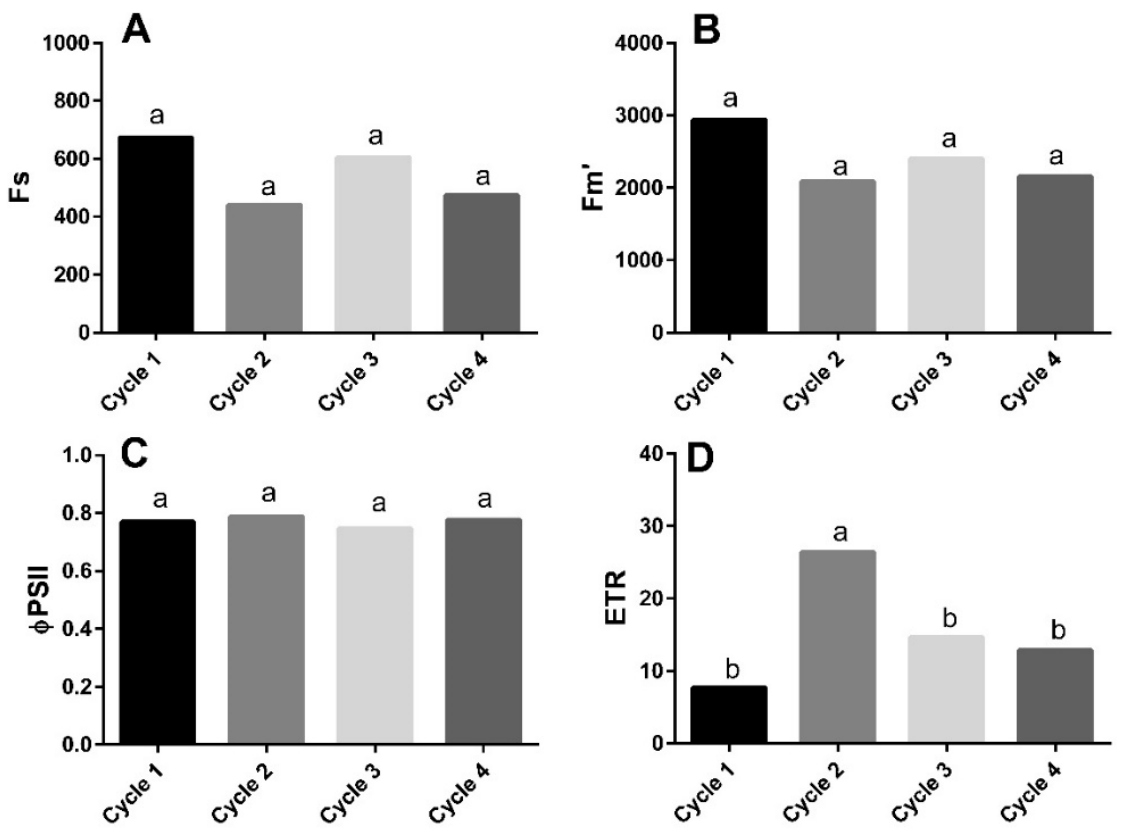

Figure 3. The chlorophyll $a$ fluorescence indexes measured in vivo on Romaine lettuce (Lactuca sativa $\mathrm{L}$. var. longifolia) leaves grown under different growing conditions, as reported in Table 1. The steady-state fluorescence yield (Fs) (A), the maximum fluorescence yield (Fm) (B), the photochemical yield of photosystem II (ФPSII) (C), and the electron transport rate (ETR) (D). Values are means \pm SE ( $n=6)$. Different letters indicate significant differences among different cycles $(p<0.05)$.

\subsection{Absorbance Spectrum of Leaves}

The light absorbance from the lettuce leaves was measured during the first growing cycle, one week after transplanting, allowing time for plant adaptation to the growing conditions, and immediately before harvest. The leaf absorbance intensity increased with plant growth, even if the shape of the spectra curve did not change. The absorbance picks of the lettuce leaves were very close to the LED emissions. For example, the highest leaf absorption in the red region was at $676 \mathrm{~nm}$ (3.75 absorption), while the LED emission was at $670 \mathrm{~nm}$ (Figure 4).

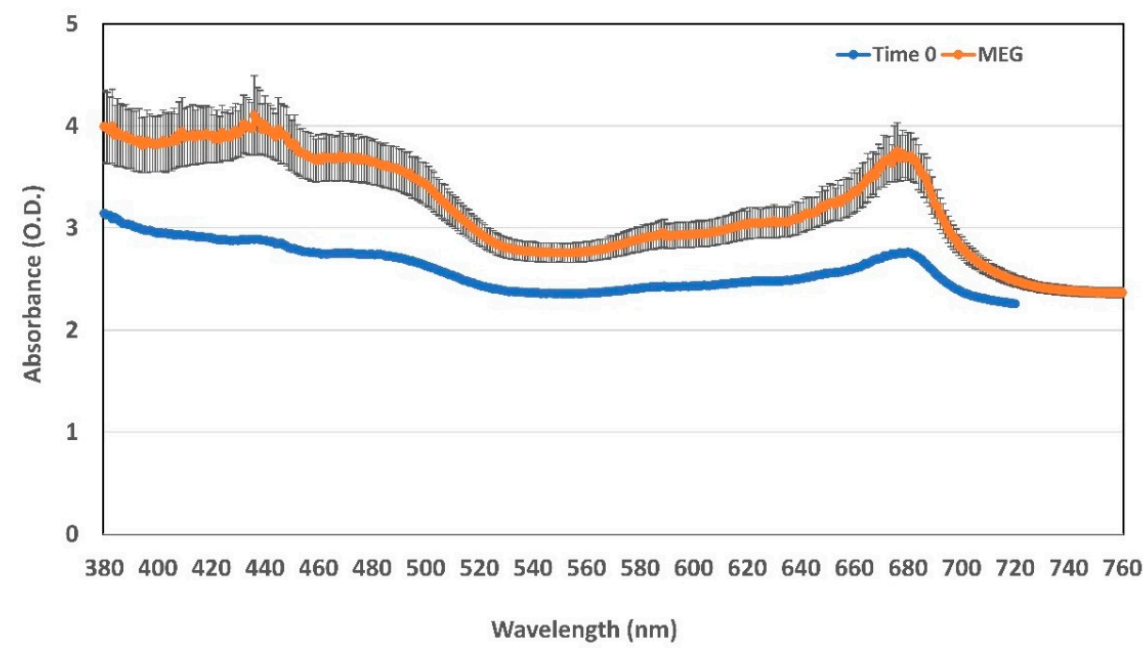

Figure 4. The leaf absorption spectra measured in the leaves of Romaine lettuce (Lactuca sativa L. var. longifolia) at the transplanting stage (Time 0 ) and one day before harvest (MEG). The absorbance curve is the mean of three single spectra recorded from three leaves of three different plants. Bars represent the standard error of the mean. 


\subsection{Plant Biomass Measurement and Estimation of the Input of Electrical Energy Consumed} for Lettuce Production

The length of the growing cycle ranged from 25 to 27 days and it was inversely correlated with the light intensity: Higher light intensity corresponded to a shorter growing cycle length (Table 1).

The yield was measured as the head biomass production for each plant. The number of fresh leaves was significantly affected by the different lighting regimes applied in this study (Figure 5A). The maximum value obtained was in plants subjected to the highest PPFD (Cycle 1, more than $280 \mathrm{~g} /$ head) while those from Cycle 4 showed a reduction in the leaf fresh biomass, which was significantly lower compared to Cycle $1(-45 \%)$ but not to $2(-25 \%)$ or $3(-39 \%)$. Similar results were obtained for the fresh roots biomass accumulation (Figure 5B), with the minimum value in Cycle 4 (around $27 \mathrm{~g} / \mathrm{head}$ ) and the maximum in Cycle 2 (around $110 \mathrm{~g} / \mathrm{head}$ ). Analysis of the dry mass percentage showed a similar trend in leaves (Figure 5C) and in roots (Figure 5C), with the highest values recorded for Cycle 2.

Figure 6 shows the electrical energy necessary for the total production in each cycle. The conditions applied in Cycles 1 and 3 allowed the highest biomass production to be obtained with a reduced electrical energy input compared to Cycles 2 and 4, in which the relative energy consumed for each $\mathrm{kg}$ of lettuce produced was higher.
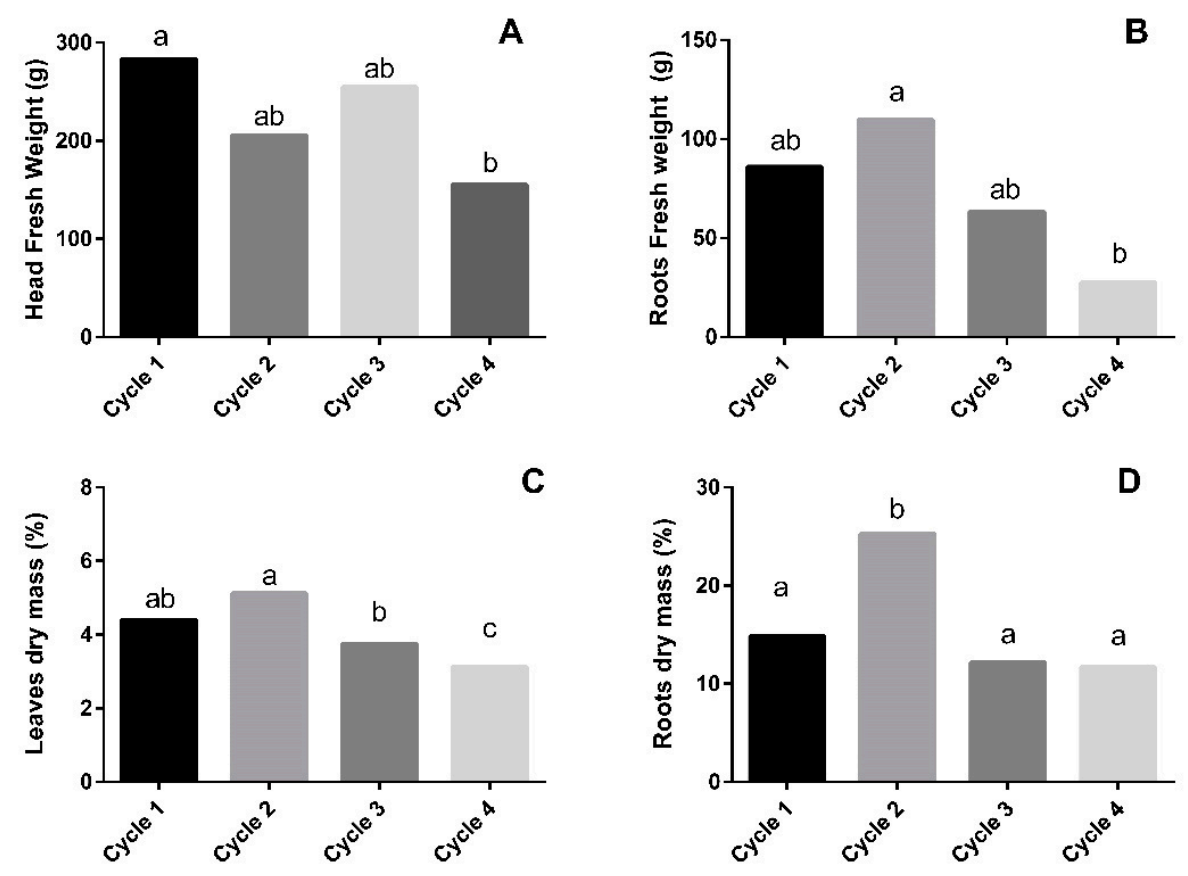

Figure 5. The biomass produced by Romaine lettuce (Lactuca sativa L. var. longifolia) leaves grown under different growing conditions, as reported in Table 1. The leaves' fresh weight (A), the roots' fresh weight (B), the leaves' percentage of dry mass $(\mathbf{C})$, and the roots' percentage of dry mass. The values are means $\pm S E(n=3)$. Different letters indicate significant differences among different cycles $(p<0.05)$. 


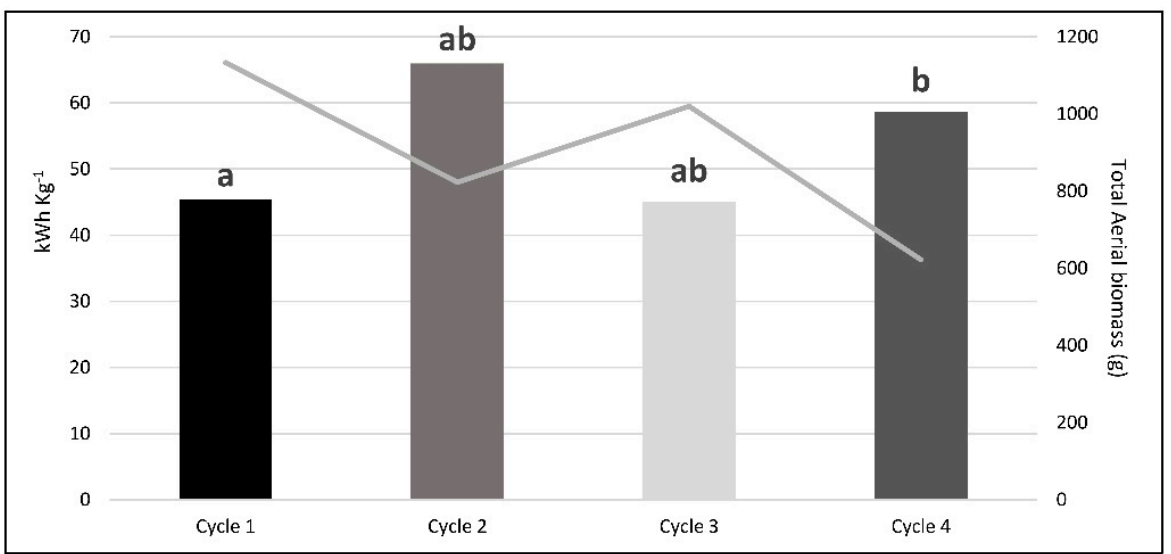

Figure 6. The left axis (histograms): The input of electrical energy consumed for Romaine lettuce (Lactuca sativa L. var. longifolia) production (KWh $\mathrm{Kg}^{-1}$ ). The right axis (line): The total fresh biomass produced in each growing cycle. Different letters indicate significant differences among different cycles $(p<0.05)$.

\subsection{Quality and Physiological Evaluation of Lettuce under Different Growing Conditions}

The leaves grown in Cycle 4 showed the highest rate of lipid peroxidation (5.35 MDA eq. $\mathrm{nmol} \mathrm{g}^{-1}$ ), however, this value was not statistically different compared to the values measured in the plants grown under the other experimental conditions (Figure 7A).

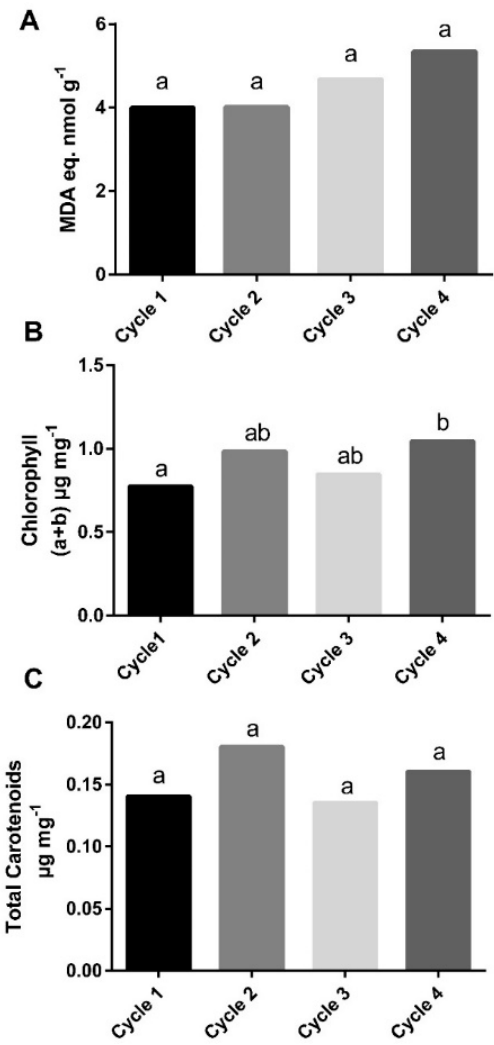

Figure 7. Lipid peroxidation expressed as malondialdehyde equivalents (MDA eq.) (A), chlorophyll content (B), and total carotenoids (C) measured in the Romaine lettuce (Lactuca sativa L. var. longifolia) leaves grown under different growing conditions, as reported in Table 1 . The values are means $\pm \mathrm{SE}$ $(\mathrm{n}=3)$. Different letters indicate significant differences among different cycles $(p<0.05)$. 
The levels of chlorophyll ( $a$ and $b$ ) that had accumulated in the leaves at the end of the cultivations were significantly lower in plants from Cycle $1\left(0.77 \mu \mathrm{g} \mathrm{mg}^{-1}\right)$. The conditions applied in Cycle 4 determined the maximum accumulation of photosynthetic pigments (around $1 \mu \mathrm{g} \mathrm{mg}^{-1}$ ), while Cycles 2 and 3 showed intermediate values (Figure 7B). The total carotenoids showed a trend like the one observed for chlorophyll, but the differences observed were not statistically significant (Figure 7C).

The carotenoid concentrations ranged from 0.14 to $0.18 \mu \mathrm{g} \mathrm{mg}^{-1}$. The total sugar content in the leaves from Cycles 2, 3, and 4 did not change in response to the different growing conditions and in all of the cycles the values obtained were between 2 and $3 \mathrm{mg} \mathrm{g}^{-1} \mathrm{FW}$ (Figure 8A). The experimental conditions applied in this trial significantly affected the level of nitrate in the leaves (Figure 8B), which was significantly higher in the plants from Cycle 3 (around $2000 \mathrm{mg} \mathrm{kg}^{-1}$ ) compared to those from Cycles 2 and 4 (below $1000 \mathrm{mg} \mathrm{kg}^{-1}$ ). An opposite trend, compared to the nitrate accumulation, was observed with the phenolic index, which was at a minimum (around 1.4) in the leaves from Cycle 3 (Figure 8C).

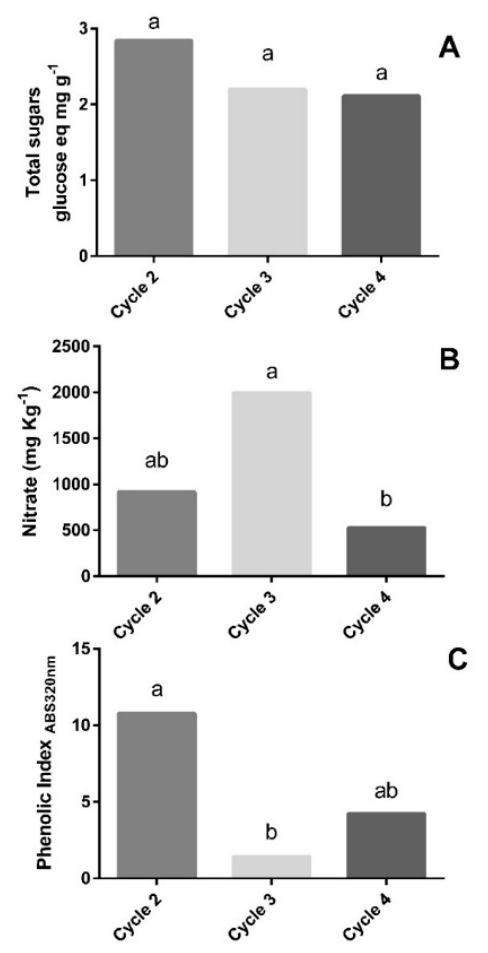

Figure 8. The total sugars (A), nitrate content (B), and phenolic index (C) measured in the Romaine lettuce (Lactuca sativa L. var. longifolia) leaves grown under different growing conditions, as reported in Table 1. Values are means \pm SE $(n=3)$. Different letters indicate significant differences among different cycles $(p<0.05)$.

\section{Discussion}

The sustainability of the cultivation system is the most critical point of indoor produce production. It can be improved through the optimization of all of the production factors, such as water, nutrients, and energy. The energy consumption largely depends on the lighting, therefore, the optimization of light emission, in terms of quality and intensity, can enable an improvement in the sustainability of all of the production system.

\subsection{Different Growing Conditions Affected Leaf Functionality}

Plants subjected to the highest light intensity and to the longest photoperiod $\left(194.54 \mu \mathrm{mol} \mathrm{m}^{-2} \mathrm{~s}^{-1}\right.$ for $16 \mathrm{~h}$, in Cycle 1) showed a significant reduction in leaf functionality, with a decline in the efficiency of PSII (Fv / Fm) and marked reductions in the PI and the ETR. These data indicated that, in Cycle 1, the light 
intensity and photoperiod were excessive for the plant needs. Under these conditions, plants showed few necrotic spots on the outer leaves (Supplementary Figure S1). Usually, under low light conditions, the light use efficiency increases, as well as the PI. This has been observed in tomato plants grown in a greenhouse, subjected to a relevant reduction in the global solar radiation (less than half of the traditional greenhouse in the same period) due to the presence of photovoltaic panels [30]. However, the yield and growing cycle length were correlated with the light intensities. The biomass and plant growth rate were directly correlated with the light availability. When red light is used as the only light source, it usually leads to a reduction in the Fv / Fm [31], but in the present study, the decrease in the chlorophyll $a$ fluorescence-related parameters was observed in the case of the lowest percentage of red light $(69.9 \%$ in Cycle 1), indicating that there was a combined effect involving blue, green, and yellow light. Consistent with what was reported by Son and Oh [31], the reduction in the quantum maximum efficiency of the PSII did not reflect a reduction in the biomass accumulation. It has been reported that the progressive incrementation of the irradiance $\left(100,300,500\right.$, and $700 \mu \mathrm{mol} \mathrm{m}^{-2} \mathrm{~s}^{-1}$ [32] or 60,140, and $220 \mu \mathrm{mol} \mathrm{m}{ }^{-2}$ $\mathrm{s}^{-1}$ [33]) would result in an incrementation of photosynthesis in the lettuce. The net photosynthesis has not been measured in this study, but considering the analysis of chlorophyll $a$ fluorescence, it is plausible to assume that a similar event took place in Cycles 2, 3, and 4, but not in Cycle 1. Fu and et al. [33] showed that, unsurprisingly, the photosynthesis increased with the highest light intensity $\left(220 \mu \mathrm{mol} \mathrm{m}{ }^{-2} \mathrm{~s}^{-1}\right)$, but it was also affected by the nitrogen availability. It is thus possible to hypothesize that the nitrogen supplied in Cycle 1 was not sufficient to sustain the photosynthesis in plants subjected to $194.54 \mu \mathrm{mol}$ $\mathrm{m}^{-2} \mathrm{~s}^{-1}$ for $16 \mathrm{~h}$ and that, possibly, plants grown under high light intensity would have benefited from an increment in the nitrogen availability in the nutrient solution. Moreover, the plants harvested from Cycle 1 showed evident changes in morphology, appearing stocky with leaves that were too thick to be considered as marketable. On the other hand, plants harvested from Cycles 2, 3, and 4 showed a positive correlation between the PPFD and the PI or ETR, confirming the previous studies cited.

The analysis of the spectrum of absorbance of the leaves can be useful for identifying the peaks of absorption in the region of the blue and red where the LEDs have the emission. The comparison of spectra data, between leaf light absorbance and LED emissions, can enable the modulation of the LED emission on the basis of plant needs. This knowledge is very important to support new crop management systems that are not only based on mineral nutrition, but also on the "lighting fertilization". In fact, in modulating the LED wavelengths, it is possible to set lamps that emit exactly on the highest absorbance peak of the crop, obtaining the highest light use efficiency (LUE) by following an adaptive control approach as recently suggested [34]. LED lighting systems enable the modulation of the intensity and wavelengths [20]. These features can be exploited for planning specific lighting recipes.

\subsection{Effect of Different Growing Conditions on Biomass Accumulation and Energy Consumption}

Generally, it is expected that a higher light intensity would result in a higher biomass accumulation [35]. An increment in the dry leaves' biomass has been observed in lettuce grown under $220 \mu \mathrm{mol} \mathrm{m}{ }^{-2} \mathrm{~s}^{-1}$ PPFD [33]. The changes in the leaves' and roots' biomass accumulation and the dry matter observed in this study are consistent with those previously observed [33]. In fact, a higher light intensity determined a higher fresh biomass production and a higher percentage of dry weight. Moreover, a low light intensity also determined a minor fresh weight accumulation and a lower dry matter percentage in roots. This could have been due to a minor photosynthates allocation to roots, as previously hypothesized $[33,36]$.

It has been suggested that, given its low energy consumption, LED technology could potentially be adopted in large-scale indoor farming [17], however, the feasibility of its use in small-scale indoor cultivation systems depended on the combined effect of several factors. The estimation of the energy input absorbed for each cycle gave quite a clear idea about how slight variation in the growing conditions (cycle length, photoperiod, light quality, and intensity) could impact on the final costs of the production, especially in small-scale systems, like those designed for indoor micro-growing. 
Considering the results obtained in this experiment, the conditions applied in Cycle 3 allowed a commercially acceptable product, in terms of the yield and quality, to be obtained, with the lowest energetic impact, while a further reduction in the energy consumption determined a significant decrease in the biomass produced. However, a more detailed investigation should be conducted to assay the exact energetic, economic, and environmental impact of this production system, perhaps considering a possible scale-up and the implementations of increasing the volume of production.

\subsection{Effect of Different Growing Conditions on Lettuce Quality and Physiological Parameters}

Quality is a key factor affecting the consumers' choices and, in the case of lettuce, it can be described using several indexes which include the visual appearance. For this reason, the chlorophyll content is an important marker for studying the physiological responses and the effects on product acceptability. Consistent with what was already observed in the lettuce [31], the chlorophyll content showed an opposite trend compared to the biomass accumulation. The lowest total chlorophyll $(a+b)$ concentration was recorded as a response to the highest PPFD and longest photoperiod (Cycle 1), while the opposite was observed for the lowest light intensity and shortest photoperiod (Cycle 4). Similar results were previously obtained in lettuce [33,37]. It has already been proposed [33] that a high light intensity could induce a lower accumulation of photosynthetic pigments, but at the same time, it can also result in higher efficiency (i.e. higher biomass accumulation) and this hypothesis can be confirmed by the data obtained in this experiment. Thus, it is possible that photosynthetic pigments increased under low light conditions to increase the light harvest [38].

Carotenoids act as photo-protective pigments and can be greatly affected by the different light quality and intensity [38]. It has been observed that, in lettuce, carotenoids showed a quadratic change trend, with higher values in plants grown with $140 \mu \mathrm{mol} \mathrm{m} \mathrm{m}^{-2} \mathrm{~s}^{-1}$ PPFD and lower values in plants grown with higher $\left(220 \mu \mathrm{mol} \mathrm{m} \mathrm{m}^{-2} \mathrm{~s}^{-1}\right)$ or lower $\left(65 \mu \mathrm{mol} \mathrm{m} \mathrm{m}^{-2} \mathrm{~s}^{-1}\right)$ PPFD [23]. Here, a similar trend was observed, with a maximum carotenoid accumulation in plants grown with the intermediate PPFD $\left(151.41 \mu \mathrm{mol} \mathrm{m}{ }^{-2} \mathrm{~s}^{-1}\right)$, even if the differences observed in the present study were not significant. The carotenoid concentrations followed the trend of chlorophyll pigments and these results are coherent with the leaf light protection against photo-bleaching. The carotenoid represents a shield for the chlorophyll, allowing it to avoid the excess light and preventing the formation of reactive oxygen species (ROS). Based on the slight changes observed in the carotenoid levels, it can be assumed that, at a cellular level, the production of harmful ROS was efficiently maintained under control. This has been further confirmed by the lack of change in the lipid peroxidation observed in all of the samples.

As previously stated, the morphological alteration and leaf necrotic spots observed in plants grown with $194.54 \mu \mathrm{mol} \mathrm{m}{ }^{-2} \mathrm{~s}^{-1}$ PPFD negatively affected the marketability of the produce; for this reason, no quality evaluation was performed on the leaves from Cycle 1.

The sugar content is an important trait which can affect both the sensory and the nutritional value of lettuce [39]. The concentration of sugars in the leaves is generally expected to increase with light intensity, due to more efficient photosynthesis occurring. In this experiment, the amount of total sugar had a slight, but not significant, decrement in response to a lower PPFD, indicating that, in this case, the sensory and nutritional characteristics of the product were not markedly affected by the reduced light intensity in Cycles 3 and 4. Recently, it has been shown that in lettuce, red light induced a higher accumulation of starch and sucrose in leaves, while limiting net photosynthesis [22]. However, in the present study, variations in the red-light percentage did not influence the sugar levels in the lettuce leaves.

As with other leafy greens, lettuce tends to accumulate high levels of nitrate, which is an important quality parameter in leafy vegetables, as it is considered to be harmful to human health $[14,40]$. For this reason, the amount of nitrate in foods is subjected to European regulation (EU: 1258/2011). This experiment showed that the nitrate level can be controlled in indoor growing systems by setting up a proper nutrient solution and that it can also be further affected by light management. In fact, 
the nitrate amount always complied with the limits imposed by the EU regulation. The highest nitrate concentration was found in samples from Cycle 3. This is probably because of the change in the red/blue ratio. In fact, it was reported that different alternating intervals of red and blue light can be effective in reducing the nitrate content in lettuce [5]. On the other hand, the minimum nitrate level was observed in leaves from Cycle 4, when the red light was at a maximum percentage, but the intensity was alternating. This could support the hypothesis that red light could improve the activity of nitrate reductase, as previously suggested [16].

Phenolic compounds are important determinants in the nutraceutical value of vegetable crops, including lettuce [41]. Different stressors can stimulate the biosynthesis or the accumulation of specific molecules belonging to this group [42-44]. In this study, the highest value of the phenolic index was found in leaves from Cycle $2\left(151.41 \mu \mathrm{mol} \mathrm{m} \mathrm{m}^{-2} \mathrm{~s}^{-1}\right)$, which could be explained by thinking that the highest percentage of blue light $(6.9 \%)$ could have had a role in stimulating the accumulation of phenolic compounds, as previously reported in lettuce [10,45]. Moreover, Son and Oh [31] showed that the activity of the enzyme phenylalanine ammonia lyase (PAL) can be stimulated by increasing the blue light.

\section{Conclusions}

The quality of the lettuce grown in an indoor cultivation system can be positively affected by modulating the light quality and intensity, as well as the other agronomical factors. This would help by increasing the efficiency of the crop light energy usage. In this experiment, it was possible to individuate the optimal conditions for growing Romaine lettuce in a closed environment (Cycle 3) and for obtaining a commercially acceptable product, in terms of the yield and quality, with the lowest energetic impact possible. In the future, it will also be possible to design an integrated system which is able to monitor the plant conditions and, in turn, to adapt the growing parameters (such as light, nutrient solution compositions, temperature, and humidity) to respond to the plant requirements in a real-time manner. Future research will also aim to identify the optimal light recipes to improve the nutritional, nutraceutical, and sensory quality of various vegetables, thereby increasing the economic value of their production. On the other hand, the use of this cultivation system will increase the level of knowledge on the mechanisms of plant-light perception and on the regulation of important metabolic pathways in response to specific kinds of light.

Even though technological innovation is offering a wide array of possibilities and solutions for growing plants almost everywhere, the energy demand is still the main limiting factor of these cultivation systems. For this reason, it is necessary to evaluate and consider the feasibility of these solutions in the proper context, thus economic and environmental studies will be needed to assay the real sustainability of such innovative growing systems on a larger scale.

Supplementary Materials: The following are available online at http:/ /www.mdpi.com/2071-1050/11/3/841/s1, Figure S1: Romaine lettuce plants harvested from Cycle 1 (A) and comparison with a lettuce plant grown in a traditional greenhouse (B).

Author Contributions: D.L.: Substantial contribution to the experimental work, first drafting, and critical revision of the manuscript; G.C.: Data analysis and interpretation, drafting, and the final preparation of the manuscript; P.S.: Support with the experimental design, lighting technologist, analysis of the light spectra, and critical revision of the manuscript; A.F.: Experimental design and coordination of the work, interpretation of the data, and critical revision of the manuscript.

Conflicts of Interest: The author Piero Santoro is employed by the company MEG S.r.l. All other authors declare no competing interests. 


\section{References}

1. Bian, Z.; Jiang, N.; Grundy, S.; Lu, C. Uncovering LED light effects on plant growth: New angles and perspectives-LED light for improving plant growth, nutrition and energy-use efficiency. Acta Hortic. 2017, 1227, 491-498. [CrossRef]

2. Han, T.; Vaganov, V.; Cao, S.; Li, Q.; Ling, L.; Cheng, X.; Peng, L.; Zhang, C.; Yakovlev, A.N.; Zhong, Y.; et al. Improving "color rendering" of LED lighting for the growth of lettuce. Sci. Rep. 2017, 7, 45944. [CrossRef] [PubMed]

3. Singh, D.; Basu, C.; Meinhardt-Wollweber, M.; Roth, B. LEDs for energy efficient greenhouse lighting. Renew. Sustain. Energy 2015, 49, 139-147. [CrossRef]

4. Bourget, C.M. An introduction to light-emitting diodes. HortScience 2008, 43, 1944-1946. [CrossRef]

5. Chen, X.L.; Yang, Q.C.; Song, W.P.; Wang, L.C.; Guo, W.Z.; Xue, X.Z. Growth and nutritional properties of lettuce affected by different alternating intervals of red and blue LED irradiation. Sci. Hortic. 2017, 223, 44-52. [CrossRef]

6. Olle, M.; Viršile, A. The effects of light-emitting diode lighting on greenhouse plant growth and quality. Agric. Food Sci. 2013, 22, 223-234. [CrossRef]

7. Goins, G.D.; Ruffe, L.M.; Cranston, N.A.; Yorio, N.C.; Wheeler, R.M.; Sager, J.C. Salad crop production under different wavelengths of red light-emitting diodes (LEDs). In Proceedings of the 31st International Conference on Environmental Systems, Orlando, FA, USA, 9-12 July 2001; pp. 1-9.

8. Lee, M.J.; Son, K.H.; Oh, M.M. Increase in biomass and bioactive compounds in lettuce under various ratios of red to far-red LED light supplemented with blue LED light. Hortic. Environ. Biotechnol. 2016, 57, $139-147$. [CrossRef]

9. Li, Q.; Kubota, C. Effects of supplemental light quality on growth and phytochemicals of baby leaf lettuce. Environ. Exp. Bot. 2009, 67, 59-64. [CrossRef]

10. Stutte, G.W.; Edney, S.; Skerritt, T. Photoregulation of bioprotectant content of red leaf lettuce with light-emitting diodes. HortScience 2009, 44, 79-82. [CrossRef]

11. Kim, H.H.; Wheeler, R.; Sager, J.; Norikane, J. Photosynthesis of lettuce exposed to different short-term light qualities. Environ. Control Biol. 2005, 43, 113-119. [CrossRef]

12. Mizuno, T.; Amaki, W.; Watanabe, H. Effects of monochromatic light irradiation by LED on the growth and anthocyanin contents in leaves of cabbage seedlings. Acta Hortic. 2009, 907, 179-184. [CrossRef]

13. Demotes-Mainard, S.; Péron, T.; Corot, A.; Bertheloot, J.; Le Gourrierec, J.; Pelleschi-Travier, S.; Crespel, L.; Morel, P.; Huché-Thélier, L.; Boumaza, R.; et al. Plant responses to red and far-red lights, applications in horticulture. Environ. Exp. Bot. 2016, 121, 4-21. [CrossRef]

14. Cavaiuolo, M.; Ferrante, A. Nitrates and glucosinolates as strong determinants of the nutritional quality in rocket leafy salads. Nutrients 2014, 6, 1519-1538. [CrossRef] [PubMed]

15. Samuolienè, G.; Brazaitytè, A.; Sirtautas, R.; Novičkovas, A.; Duchovskis, P. Supplementary red-LED lighting affects phytochemicals and nitrate of baby leaf lettuce. J. Food Agric. Environ. 2011, 9, 271-274.

16. Samuolienè, G.; Urbonavičiūtè, A.; Duchovskis, P.; Bliznikas, Z.; Vitta, P.; Žukauskas, A. Decrease in nitrate concentration in leafy vegetables under a solid-state illuminator. HortScience 2009, 44, 1857-1860. [CrossRef]

17. Wheeler, R.M. Agriculture for space: People and places paving the way. Open Agric. 2017, 2, 14-32. [CrossRef]

18. Yeh, N.; Chung, J.P. High-brightness LEDs-Energy efficient lighting sources and their potential in indoor plant cultivation. Renew. Sustain. Energy 2009, 13, 2175-2180. [CrossRef]

19. Kikuchi, Y.; Kanematsu, Y.; Yoshikawa, N.; Okubo, T.; Takagaki, M. Environmental and resource use analysis of plant factories with energy technology options: A case study in Japan. J Clean. Prod. 2018, 186, $703-717$. [CrossRef]

20. Cocetta, G.; Casciani, D.; Bulgari, R.; Musante, F.; Kołton, A.; Rossi, M.; Ferrante, A. Light use efficiency for vegetables production in protected and indoor environments. EPJ Plus 2017, 132, 43. [CrossRef]

21. Avercheva, O.V.; Berkovich, Y.A.; Konovalova, I.O.; Radchenko, S.G.; Lapach, S.N.; Bassarskaya, E.M.; Kochetovaa, G.V.; Zhigalova, T.V.; Yakovlevad, O.T.; Tarakanov, I.G. Optimizing LED lighting for space plant growth unit: Joint effects of photon flux density, red to white ratios and intermittent light pulses. Life Sci. Space Res. 2016, 11, 29-42. [CrossRef]

22. Wang, J.; Lu, W.; Tong, Y.; Yang, Q. Leaf morphology, photosynthetic performance, chlorophyll fluorescence, stomatal development of lettuce (Lactuca sativa L.) exposed to different ratios of red light to blue light. Front. Plant Sci. 2016, 7, 250. [CrossRef] [PubMed] 
23. Živčák, M.; Brestič, M.; Olšovská, K.; Slamka, P. Performance index as a sensitive indicator of water stress in Triticum aestivum L. Plant Soil Environ. 2008, 54, 133-139. [CrossRef]

24. Heath, R.L.; Packer, L. Photoperoxidation in isolated chloroplasts: II. Role of electron transfer. Arch. Biochem. Biophys. 1968, 125, 850-857. [CrossRef]

25. Lichtenthaler, H.K. Chlorophylls and carotenoids: Pigments of photosynthetic biomembranes. In Methods in Enzymology; Academic Press: Cambridge, MA, USA, 1987; Volume 148, pp. 350-382.

26. Yemm, E.W.; Willis, A.J. The estimation of carbohydrates in plant extracts by anthrone. Biochem. J. 1954, 57, 508-514. [CrossRef] [PubMed]

27. Cataldo, D.A.; Maroon, M.; Schrader, L.E.; Youngs, V.L. Rapid colorimetric determination of nitrate in plant tissue by nitration of salicylic acid. Commun. Soil Sci. Plant Anal. 1975, 6, 71-80. [CrossRef]

28. Ke, D.; Saltveit, M.E. Wound-induced ethylene production, phenolic metabolism and susceptibility to russet spotting in iceberg lettuce. Physiol. Plant. 1989, 76, 412-418. [CrossRef]

29. Maxwell, K.; Johnson, G.N. Chlorophyll fluorescence-A practical guide. J. Exp. Bot. 2000, 51, 659-668. [CrossRef]

30. Bulgari, R.; Cola, G.; Ferrante, A.; Franzoni, G.; Mariani, L.; Martinetti, L. Micrometeorological environment in traditional and photovoltaic greenhouses and effects on growth and quality of tomato (Solanum lycopersicum $\mathrm{L}$.). Ital. J. Agrometeorol. 2015, 20, 27-38.

31. Son, K.H.; Oh, M.M. Leaf shape, growth, and antioxidant phenolic compounds of two lettuce cultivars grown under various combinations of blue and red light-emitting diodes. HortScience 2013, 48, 988-995. [CrossRef]

32. Qin, L.; Guo, S.; Ai, W.; Tang, Y. Selection of candidate salad vegetables for controlled ecological life support system. Adv. Space Res. 2008, 41, 768-772. [CrossRef]

33. Fu, Y.; Li, H.; Yu, J.; Liu, H.; Cao, Z.; Manukovsky, N.S.; Liu, H. Interaction effects of light intensity and nitrogen concentration on growth, photosynthetic characteristics and quality of lettuce (Lactuca sativa L. Var. youmaicai). Sci. Hortic. 2017, 214, 51-57. [CrossRef]

34. van Iersel, M.W.; Gianino, D. An Adaptive Control Approach for Light-emitting Diode Lights Can Reduce the Energy Costs of Supplemental Lighting in Greenhouses. HortScience 2017, 52, 72-77. [CrossRef]

35. Jishi, T.; Kimura, K.; Matsuda, R.; Fujiwara, K. Effects of temporally shifted irradiation of blue and red LED light on cos lettuce growth and morphology. Sci. Hortic. 2016, 198, 227-232. [CrossRef]

36. Poorter, H.; Niklas, K.J.; Reich, P.B.; Oleksyn, J.; Poot, P.; Mommer, L. Biomass allocation to leaves, stems and roots: Meta-analyses of interspecific variation and environmental control. New Phytol. 2012, 193, 30-50. [CrossRef] [PubMed]

37. Yorio, N.C.; Goins, G.D.; Kagie, H.R.; Wheeler, R.M.; Sager, J.C. Improving spinach, radish, and lettuce growth under red light-emitting diodes (LEDs) with blue light supplementation. HortScience 2001, 36, 380-383. [CrossRef] [PubMed]

38. Carvalho, R.F.; Takaki, M.; Azevedo, R.A. Plant pigments: The many faces of light perception. Acta Physiol. Plant. 2011, 33, 241-248. [CrossRef]

39. Lin, K.H.; Huang, M.Y.; Huang, W.D.; Hsu, M.H.; Yang, Z.W.; Yang, C.M. The effects of red, blue, and white light-emitting diodes on the growth, development, and edible quality of hydroponically grown lettuce (Lactuca sativa L. var. capitata). Sci. Hortic. 2013, 150, 86-91. [CrossRef]

40. Iammarino, M.; Di Taranto, A.; Cristino, M. Monitoring of nitrites and nitrates levels in leafy vegetables (spinach and lettuce): A contribution to risk assessment. J. Sci. Food Agric. 2014, 94, 773-778. [CrossRef]

41. Tomás-Barberán, F.A.; Espín, J.C. Phenolic compounds and related enzymes as determinants of quality in fruits and vegetables. J. Sci. Food Agric. 2001, 81, 853-876. [CrossRef]

42. Oh, M.M.; Carey, E.E.; Rajashekar, C.B. Environmental stresses induce health-promoting phytochemicals in lettuce. Plant Physiol. Biochem. 2009, 47, 578-583. [CrossRef]

43. Samuoliené, G.; Sirtautas, R.; Brazaitytè, A.; Duchovskis, P. LED lighting and seasonality effects antioxidant properties of baby leaf lettuce. Food Chem. 2012, 134, 1494-1499. [CrossRef] [PubMed] 
44. Pérez-López, U.; Sgherri, C.; Miranda-Apodaca, J.; Micaelli, F.; Lacuesta, M.; Mena-Petite, A.; Quartaccia, F.M.; Muñoz-Rueda, A. Concentration of phenolic compounds is increased in lettuce grown under high light intensity and elevated $\mathrm{CO}_{2}$. Plant Physiol. Biochem. 2018, 123, 233-241. [CrossRef] [PubMed]

45. Johkan, M.; Shoji, K.; Goto, F.; Hashida, S.N.; Yoshihara, T. Blue light-emitting diode light irradiation of seedlings improves seedling quality and growth after transplanting in red leaf lettuce. Hortic. Sci. 2010, 45, 1809-1814. [CrossRef]

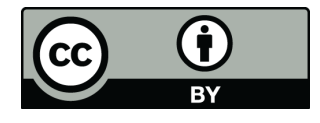

(C) 2019 by the authors. Licensee MDPI, Basel, Switzerland. This article is an open access article distributed under the terms and conditions of the Creative Commons Attribution (CC BY) license (http://creativecommons.org/licenses/by/4.0/). 